\title{
Cultivating reading self-efficacy
}

Lance P. Burrows

School of Economics, Kinki University, Japan

https://doi.org/10.36505/ExLing-2012/05/0008/000214

\begin{abstract}
This study is a longitudinal investigation, conducted over one academic year, into the role that extensive reading (ER) and reading strategies play in the cultivation of reading self-efficacy in an English as a foreign language (EFL) context. The study also examined how changes in reading self-efficacy relate to changes in reading proficiency. The participants $(N=322)$ were non-English major students at a university in Japan. The data for the study was obtained through a battery of Likertscale questionnaires and reading comprehension tests. The results revealed that a combination of reading strategy intervention and participation in an extensive reading program would lead to greater gains in reading self-efficacy which was also later shown to translate into gains in reading comprehension.
\end{abstract}

Key words: self-efficacy, extensive reading, language testing, reading strategies

\section{Review of the literature}

Self-belief and its influence on reading development is one dimension of this reading motivation. The role that self-belief plays in English as a foreign language reading motivation has been investigated (e.g., Mori, 2002) and empirical results indicate that there is a strong relationship between reading motivation and reading self-efficacy beliefs. However, research investigating methods by which reading self-efficacy may be cultivated in an EFL context are lacking.

\section{Self-efficacy}

In his article entitled "Self-Efficacy: Toward a Unifying Theory of Behavioral Change," Bandura (1977) defined self-efficacy as the strength of expectations individuals maintain about their ability to perform successfully a behavior that will lead to a particular outcome. He further claims that one's level of self-efficacy relates strongly to one's decision to initiate activities that support learning, the level of effort expended on accomplishing those activities, and how perseverant that person can be in the face of adversity.

\section{Reading strategies and extensive reading}

As mentioned above, reading self-efficacy plays a significant role in reading motivation, therefore, methods of teaching that might promote self-efficacy in the EFL context were investigated. Reading strategy intervention and extensive reading showed great promise.

Schunk and Rice (1987) found through studies with L1 remedial learners that explicit instruction to students on the use and utility of reading comprehension strategies helped them not only comprehend

ExLing 2012: Proceedings of 5th Tutorial and Research Workshop on Experimental Linguistics, 27-29 August 2012, Athens, Greece 
better, it also helped to improve their reading self-efficacy. Schunk et al. (1991) also demonstrated that children's sense of efficacy is closely connected to their academic performance, and that instructing students both on how to be more efficacious would lead to learners' engagement in the reading process.

In addition to reading strategies, ER has also shown some positive affective benefits to learners. Nishino (2007) conducted a longitudinal, case study of two teenage EFL learners in Japan in which her data supported the notion that ER fosters a stronger sense of motivation and attitude toward reading in the $\mathrm{L} 2$.

Takase (2003) also reported gains in motivation of 219 Japanese EFL high school students related to ER program participation. She found that the motivation of the participants was multifaceted with the strongest element in extensive reading motivation being intrinsic motivation.

In the end, an investigation into the effects that reading strategies and extensive reading have on reading self-efficacy was undertaken with the following research questions:

1. To what degree does the participants' English reading self-efficacy change after participation in one of the three experimental groups or the intensive reading group (control group) over one academic year?

2. Do changes in reading self-efficacy lead to changes in reading comprehension?

\section{Methods}

The study was conducted with the cooperation of 322 first- and second-year non-English major university students enrolled in 14 intact English reading classes in Japan. All participants were native Japanese speakers and were divided into four groups: an extensive reading group that only practiced extensive reading, a reading strategies group that was only instructed on the use of reading strategies, a combination of ER/reading strategies group that practiced both methods, and a control group. The control group classes were conducted using intensive reading methods.

\section{Instrumentation}

One questionnaire measuring changes in reading self-efficacy and one reading comprehension test were given three times over the academic year.

\section{Results}

The data of the questionnaire and the reading comprehension tests were analyzed using MANOVAs and Latent Growth Curve Modeling. 
A MANOVA was conducted with the independent variable being the four groups and the dependent variable being the gain scores for reading selfefficacy taken the three times over the course of the study. The participants in the reading strategies and extensive reading/reading strategies groups gained significantly more from time 1 to time 3 in reading self-efficacy than those in the ER and control groups (Figure 1).

\section{Results for Research Question 1}

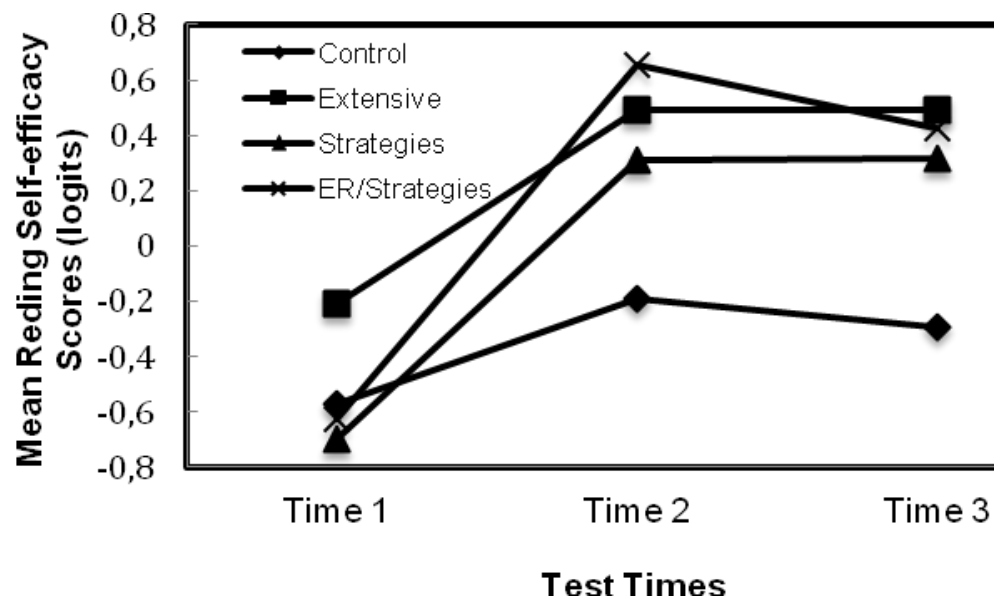

Figure 1. Mean reading self-efficacy scores for all groups.

\section{Results for Research Question 2}

A latent growth curve was conducted to determine if changes in reading selfefficacy lead to changes in reading comprehension. The associative model depicted in Figure 2 illustrates the initial changes in reading self-efficacy (InterceptSE) have a minimal and negative effect on changes in reading comprehension (SlopeRC). However, changes in reading self-efficacy (SlopeSE) show a fairly strong effect on change in reading comprehension (SlopeRC). 


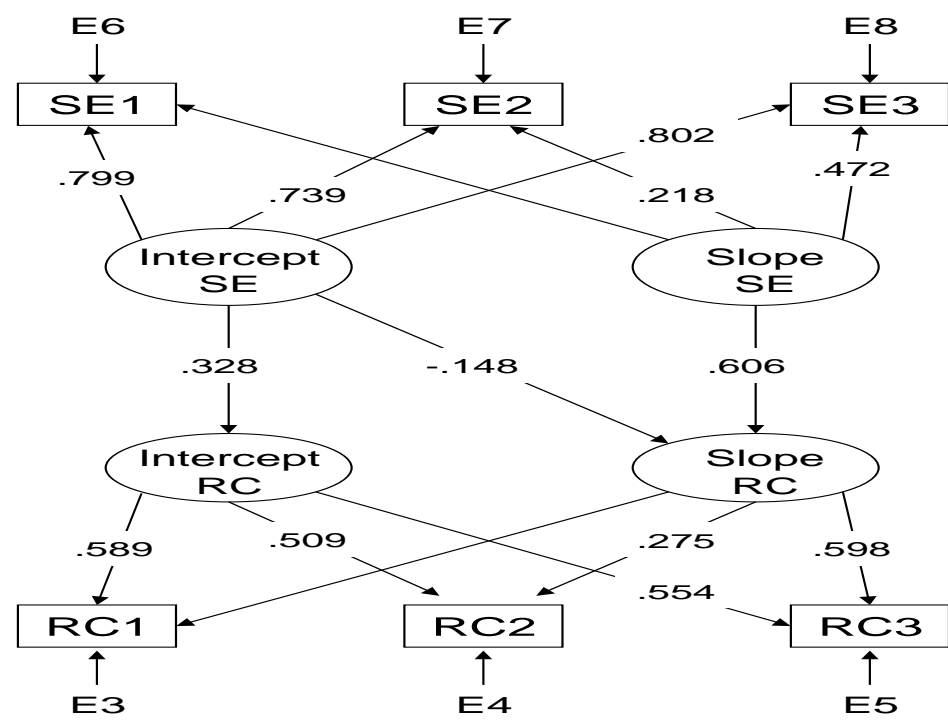

Figure 2. Latent growth curve for changes in reading self-efficacy predicting changes in reading comprehension.

\section{Conclusion}

These results underscore the importance of self-efficacy in the learning process and how the cultivation of self-efficacy can lead to the improvement of reading comprehension.

\section{References}

Bandura, A. 1977. Self-efficacy: Toward a unifying theory of behavioral change. Psychological Review, 84, 191-215.

Mori, S. 2002. The relationship between motivation and the amount of out-of class reading . Unpublished Doctoral dissertation. Temple University.

Nishino, T. 2007. Beginning to read extensively. Reading in a Foreign Language, 19, 76-105. (AN 27165531).

Schunk, D.H. 1989a. Self-efficacy and achievement behaviors. Educational Psychology Review, 1, 173-208.

Schunk, D.H. 1991. Self-efficacy and academic motivation. Educational Psychologist, 26, 207-231.

Takase, A. 2003. The effects of extensive reading on the motivation of Japanese high school students. Unpublished doctoral dissertation. Temple University, Japan. 